\title{
Comparison of aerosol optical and microphysical retrievals from HSRL-2 and in-situ measurements during DISCOVER-AQ 2013 (California and Texas)
}

\author{
Patricia Sawamura ${ }^{1,2, *}$, Detlef Müller ${ }^{3}$, Sharon Burton ${ }^{1}$, Eduard Chemyakin ${ }^{1,4}$, Chris Hostetler ${ }^{1}$, \\ Richard Ferrare $^{1}$, Alexei Kolgotin ${ }^{\mathbf{5}}$, Luke Ziemba ${ }^{1}$, Andreas Beyersdorf ${ }^{\mathbf{1}}$, Bruce Anderson ${ }^{1}$ \\ ${ }^{I}$ NASA Langley Research Center, Hampton, VA, USA, *Email: patricia.sawamura@nasa.gov, ${ }^{2}$ Oak \\ Ridge Associated Universities, TN, USA, ${ }^{3}$ University of Hertfordshire, UK, ${ }^{4}$ Science System and \\ Applications Inc., Hampton, VA, USA, ${ }^{5}$ Physics Instrumentation Center, Troitsk, Russia
}

\begin{abstract}
The combination of backscatter coefficients measured at 355, 532 and $1064 \mathrm{~nm}$ and extinction coefficients at 355 and $532 \mathrm{~nm}$ (i.e. $3 \beta+2 \alpha$ ) can be used to retrieve profiles of optical and microphysical properties of aerosols, such as effective radius, total volume concentration and total number concentration. NASA LaRC HSRL-2 is an airborne multi-wavelength high spectral resolution lidar in operation that provides the full $3 \beta+2 \alpha$ dataset. HSRL-2 was deployed during DISCOVER-AQ along with other airborne and ground-based instruments that also measured many aerosol parameters in close proximity to the HSRL-2 system, allowing us to evaluate the performance of an automated and unsupervised retrieval algorithm that has been recently developed. We present the results from California (Jan/Feb 2013) and Texas (Sep 2013) DISCOVER-AQ.
\end{abstract}

\section{INTRODUCTION}

Since 2012, the NASA LaRC airborne HSRL-2 has been measuring backscatter coefficients at 355,532 , and $1064 \mathrm{~nm}$ and extinction coefficients at 355 and $532 \mathrm{~nm}$ (i.e. $3 \beta+2 \alpha$ ) on field missions. This lidar is an airborne prototype of the multiwavelength HSRL envisioned for the NASA Aerosol-Clouds-Ecosystem (ACE) satellite mission being formulated in response to the NRC Decadal Study recommendation.

The $3 \beta+2 \alpha$ lidar technique allows for the retrieval of microphysical properties of aerosols, such as particle size distributions and complex refractive index [1]. In order to handle the inversion of extensive satellite datasets, an automated and unsupervised microphysics retrieval algorithm has been recently developed [2]. The results from HSRL-2 first deployment during TCAP 2012 showed good agreement with in-situ measurements [2].

HSRL-2 was also deployed during DISCOVERAQ (Deriving Information on Surface Conditions from Column and VERtically Resolved Observations Relevant to Air Quality) onboard NASA Langley's B-200 aircraft in 2013 (Jan/Feb: California, Aug/Sep: Texas) and 2014 (Jul/Aug: Colorado). During DISCOVER-AQ in-situ instruments were also deployed onboard NASA Wallops' P3B aircraft that flew in ascending/descending spirals over a number of locations collecting vertical profile measurements of optical, physical and chemical properties of aerosols and trace gases.

These coincident airborne in-situ measurements provide an opportunity for continued evaluation of the HSRL-2 retrievals. In this paper we examine aerosol measurements and retrievals obtained from in-situ and HSRL-2 measurements during the two deployments of DISCOVER-AQ 2013 (California and Texas).

\section{METHODOLOGY}

The HSRL-2 and in-situ measurements were obtained onboard two different aircraft. Therefore, in order to compare the HSRL-2 measurements/ retrievals to the in-situ measurements, a radius of colocation was set to 20 and $10 \mathrm{~km}$ for California and Texas, respectively. The longest period of time allowed between lidar and in-situ measurements was 30 minutes for both locations.

From the in-situ set of measurements we used: the scattering coefficients measured at 450,550 , and $700 \mathrm{~nm}$ with a TSI nephelometer, absorption coefficient at $532 \mathrm{~nm}$ measured with a Particle Soot Absorption Photometer (PSAP), and size 
distributions obtained with an Ultra-High Sensitivity Aerosol Spectrometer (UHSAS) that measures particles in the $60 \mathrm{~nm}-1 \mu \mathrm{m}$ optical diameter range. Most measurements were obtained for low relative humidity (RH) conditions except for the scattering at $550 \mathrm{~nm}$, which was also measured at higher RH conditions (RH 80-85\%). The two (dry and wet) scattering coefficients measurements at $550 \mathrm{~nm}$ along with measurements of the ambient $\mathrm{RH}$ allow for the estimation of the scattering coefficient at ambient RH [3].

The UHSAS instrument, like most optical counters, is calibrated using polystyrene latex (PSL) spheres that are known to have a refractive index (real part) of $\sim 1.59$ at the $500-600 \mathrm{~nm}$ range. This value is higher than for most particles present in the atmosphere (except for soot). For this reason, a correction was applied in order to account for more realistic refractive index values.

After this first correction to the size distributions, the real and imaginary parts of the refractive index ( $\mathrm{mR}, \mathrm{mI}$, respectively) at low $\mathrm{RH}$ conditions (i.e. dry) are estimated from the combination of dry size distributions, dry scattering coefficients at 450, 550 and $700 \mathrm{~nm}$ and dry absorption at 532 $\mathrm{nm}$. Using a grid of $\mathrm{mR}$ and $\mathrm{mI}$ values we search for pairs that, along with the size distributions in a Mie code, allow the reproduction of the dry scattering and absorption coefficients within $20 \%$ and $2 \mathrm{Mm}^{-1}$ accuracy, respectively. It should be noted that a wavelength-independent refractive index is assumed for this step.

Lidar systems measure aerosol backscatter and/or extinction coefficients at ambient RH conditions. In order to compare the HSRL-2 aerosol measurements and retrievals to the in-situ measurements, the latter had to be adjusted to account for water uptake effects (i.e. hygroscopicity) as these measurements were originally obtained in dry conditions.

An iterative algorithm is then used to estimate diameter-independent growth factors that are used to correct the dry refractive index and size distributions for hygroscopicity effects in a manner that allows the reproduction of the measured ambient scattering coefficients at 550 $\mathrm{nm}$ within $1 \%$ accuracy. The methodology used to correct the refractive index and size distribution with growth factors is similar to the one described in [4].

At the end of this process we are able to estimate vertical profiles of complex index of refraction, surface-area, volume and effective radius at ambient RH from the in-situ measurements.

As a last step, the ambient refractive indices and size distributions are used to calculate the backscatter coefficients at 355, 532 and $1064 \mathrm{~nm}$, and extinction coefficients at 355 , and $532 \mathrm{~nm}$ in order to be compared with the HSRL-2 measurements.

Details on the automated, unsupervised microphysical retrieval algorithm that was used for the HSRL-2 data are presented in [2].

\section{RESULTS}

After applying all the necessary corrections to the in-situ size distributions we compare number, surface-area, and volume concentrations, as well as effective radius to the HSRL-2 fine mode retrievals. Figure 1 shows the results for DISCOVER-AQ Texas and Figure 2 shows the results for DISCOVER-AQ California. The colors in Figure 1 represent density of points due to the much higher number of points obtained in Texas. DISCOVER-AQ California happened during wintertime when the planetary boundary layer is usually very shallow, yielding very short profiles.

We find good agreement between HSRL-2 fine mode retrievals and humidity-corrected in-situ measurements of number, surface-area and volume concentrations for Texas and California. These results agree with the results of a case study presented in [2].

The comparison of optical data (i.e. $3 \beta+2 \alpha$ ) measured by the HSRL-2 to the reconstructed optical data from the in-situ measurements showed some disagreements which are currently being investigated. In general, the extinction coefficients show better agreement than the backscatter coefficients. Some of the possible causes for the disagreements are:

- Limitation of the UHSAS instrument to submicron particles; 

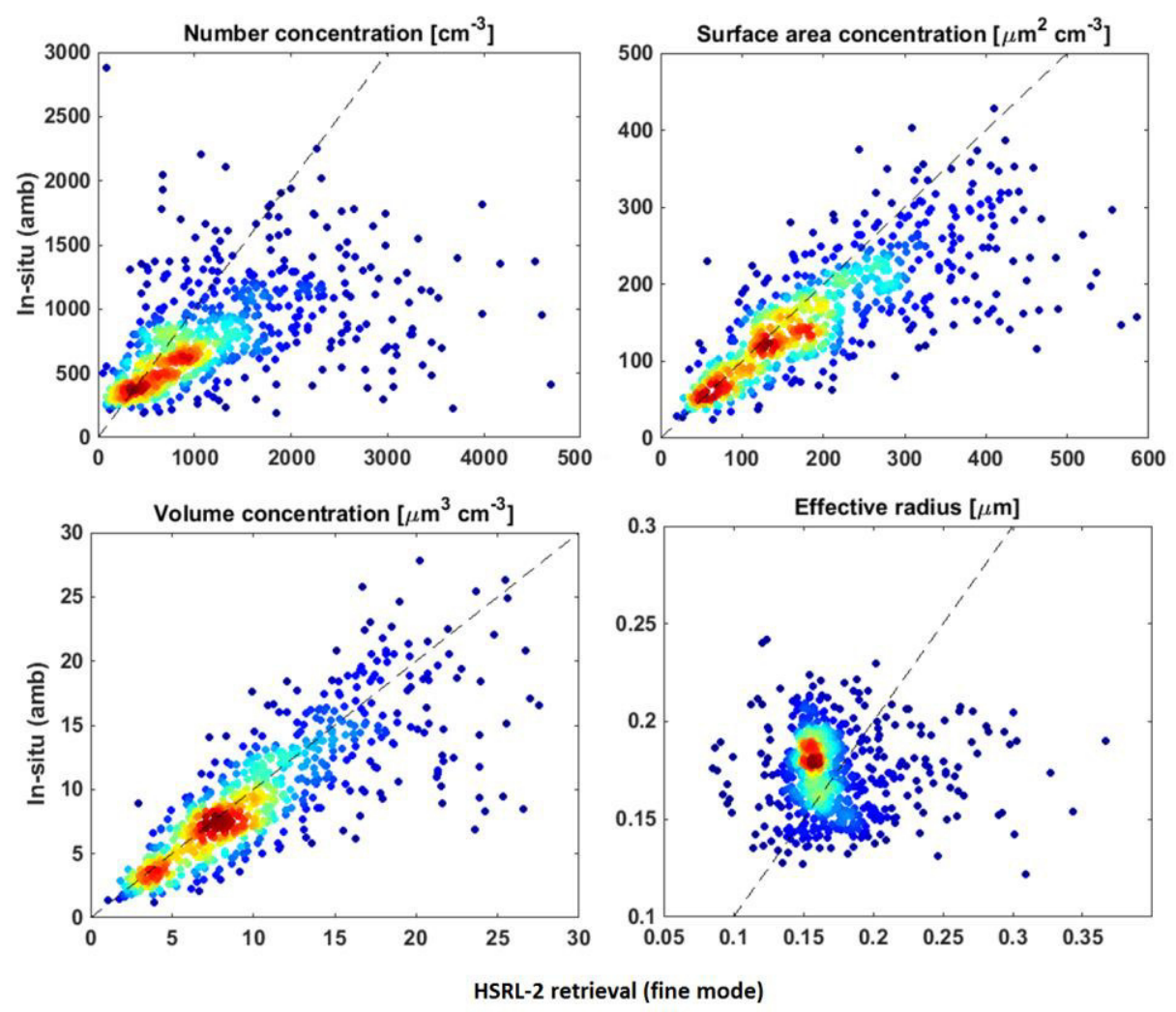

Figure 1. Comparison of size parameters retrieved from HSRL-2 (x-axis) and in-situ measurements (yaxis) from coincident profiles obtained during DISCOVER-AQ Texas (Aug-Sep 2013). Due to the large number of data points (658), a density scatter plot is presented, where warmer colors represent higher density of points.

- Estimation of imaginary refractive index (which relies strongly on the absorption coefficient measurements at one wavelength) and its correction for hygroscopic effects;

- Assumption of wavelength-independent refractive index

\section{CONCLUSIONS}

DISCOVER-AQ provided us with a great opportunity and datasets to evaluate the automated aerosol microphysics retrieval algorithm that was recently developed for the HSRL-2.

Given the different nature of remote sensing and in-situ measurements, a careful analysis is required when comparing such measurements/ retrievals. We attempted to account for differences originating from sampling method, instrument and retrieval limitations.

Compared to in-situ measurements, the current algorithm has shown good performance in retrieving size parameters such as number, surface-area, and volume concentrations, as well as effective radius.

More work is ongoing to improve the accuracy of refractive index and single-scattering albedo retrievals (not shown). 

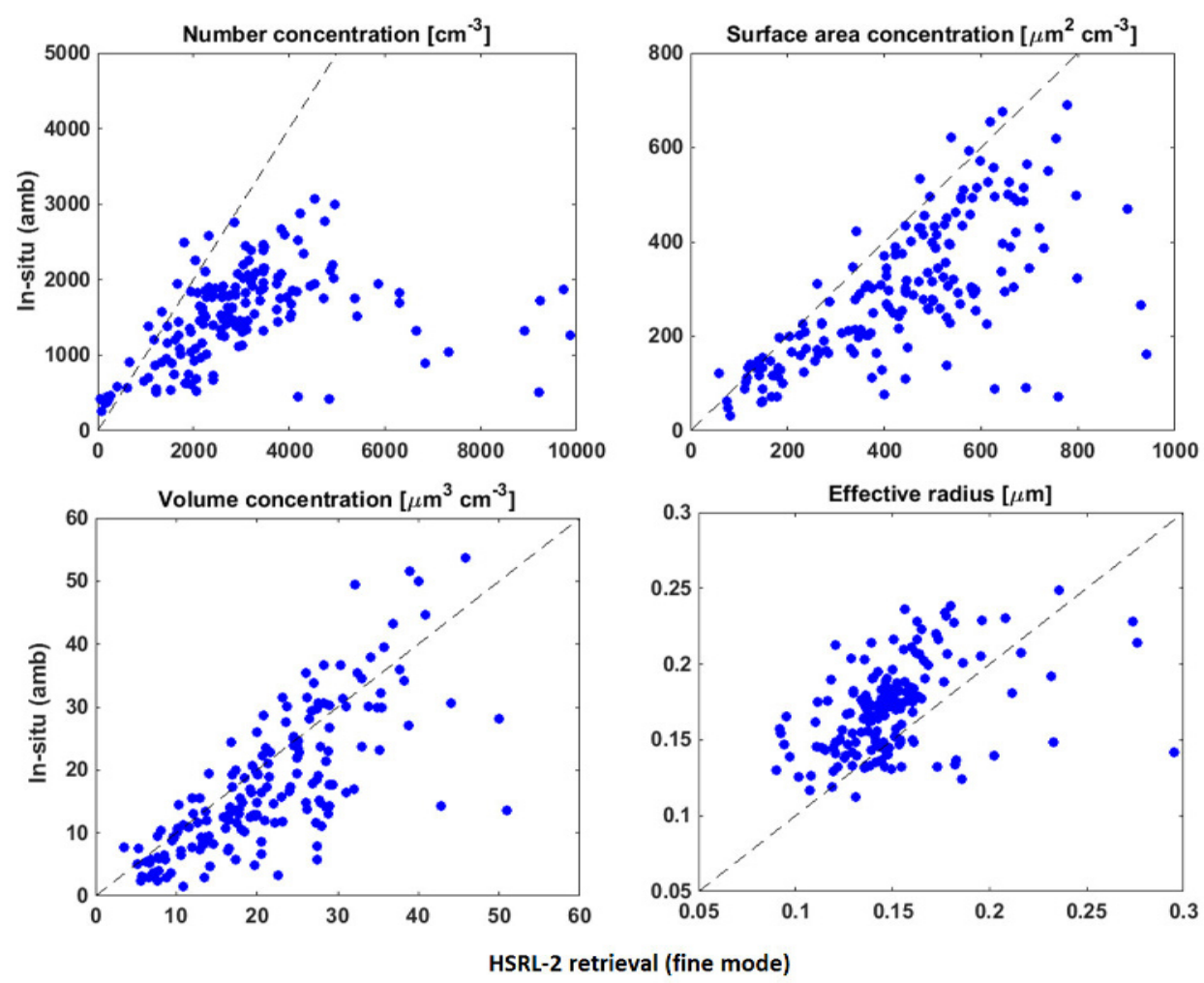

Figure 2. Comparison of size parameters retrieved from HSRL-2 (x-axis) and in-situ measurements (yaxis) from coincident profiles obtained during DISCOVER-AQ California (Jan-Feb 2013). Number of data points: 173 .

\section{ACKNOWLEDGEMENT}

This work was funded by DISCOVER-AQ and NASA Postdoctoral Program (through Oak Ridge Associated Universities). The authors would like to thank the flight crew from both NASA B200 and $\mathrm{P} 3 \mathrm{~B}$.

\section{REFERENCES}

[1] Müller, D., Wandinger, U., Althausen, D., Mattis, I., and Ansmann, A.: Retrieval of physical particle properties from lidar observations of extinction and backscatter at multiple wavelengths, Appl. Opt., 37, 2260-2263, 1998.

[2] Müller, D., Hostetler, C. A., Ferrare, R. A., Burton, S. P., Chemyakin, E., Kolgotin, A., Hair, J. W., Cook, A. L., Harper, D. B., Rogers, R. R.. Hare, R. W., Cleckner, C. S., Obland, M. D.,
Tomlinson, J., Berg, L. K., and Schmid, B.: Airborne Multiwavelength High Spectral Resolution Lidar (HSRL-2) observations during TCAP 2012: vertical profiles of optical and microphysical properties of a smoke/urban haze plume over the northeastern coast of the US, Atmos. Meas. Tech, 7, 3487-3496, 2014.

[3] Ziemba, L. D., Thornhill, K. L., Ferrare, R., Barrick, J., Beyersdorf, A. J., Chen, G., Crumeyrolle, S. N., Hair, J., Hostetler, C., Hudgins, C., Obland, M., Rogers, R., Scarino, A. J., Winstead, E. L., Anderson, B. E., Geophys. Res. Lett., 40, 417-422, 2013.

[4] Zieger, P., Fierz-Schmidhauser, R., Gysel, M., Ström, J., Henne, S., Yttri, K. E., Baltensperger, U., and Weingartner, E.: Effects of relative humidity on aerosol light scattering in the Arctic, Atmos. Chem. Phys., 10, 3875-3890, 2010. 